\title{
A Simple, Anatomically Based Correction to the Conventional Ankle Joint Center
}

Dustin A. Bruening

Brigham Young University, dabruening@byu.edu

Ashlie N. Crewe

Frank L. Buczek

Follow this and additional works at: https://scholarsarchive.byu.edu/facpub

Part of the Exercise Science Commons

\section{Original Publication Citation}

Dustin A. Bruening, Ashlie N. Crewe, Frank L. Buczek. A simple, anatomically based correction to the conventional ankle joint center. Clinical Biomechanics. Volume 23, Issue 10, December 2008, Pages 1299-1302. doi:10.1016/j.clinbiomech.2008.08.005

\section{BYU ScholarsArchive Citation}

Bruening, Dustin A.; Crewe, Ashlie N.; and Buczek, Frank L., "A Simple, Anatomically Based Correction to the Conventional Ankle Joint Center" (2008). Faculty Publications. 1626.

https://scholarsarchive.byu.edu/facpub/1626

This Peer-Reviewed Article is brought to you for free and open access by BYU ScholarsArchive. It has been accepted for inclusion in Faculty Publications by an authorized administrator of BYU ScholarsArchive. For more information, please contact ellen_amatangelo@byu.edu. 


\title{
A simple, anatomically based correction to the conventional ankle joint center
}

\author{
Dustin A. Bruening, Ashlie N. Crewe, Frank L. Buczek
}

\begin{abstract}
Background. Conventional motion analysis studies define the ankle joint center as the midpoint between the most medial and lateral aspects of the malleoli, yet research points toward a more distal joint center location. The purpose of this study was to develop and evaluate an anatomically based correction that would move the conventional ankle joint center to a more accurate location.
\end{abstract}

Methods. Lower extremity radiographs from 30 pediatric patients were analyzed retrospectively. An offset between the conventional and more accurate ankle joint centers was measured and correlated to other common anatomical measures based on conventional skin mounted marker positions. The best correlated measure was used to define a simple correction factor, which was subsequently evaluated by its effect on six degree-of-freedom ankle joint translations during normal gait $(n=8)$.

Findings. Shank length was found to have the highest bivariate linear correlation $(r=0.89)$ with the offset. Adjusting the ankle joint center using a percentage of shank length (2.7\%) was also as accurate as the regression equation in predicting offset (mean error $0.6 \mathrm{~mm}$, or $6 \%$ offset). Adjusting the ankle joint center using this simple percentage resulted in a $25 \%$ reduction in mean ankle joint translations during normal gait.

Interpretation. The accuracy of the ankle joint center can be increased through a simple, anatomically based correction. This correction may prove beneficial in some kinematic and kinetic applications requiring increased anatomical fidelity.

Keywords: Ankle joint center; Ankle axes; Joint translation; Six-degree-of-freedom modeling; Gait analysis

\section{Introduction}

Conventional motion analysis studies define the center of the ankle joint (i.e., the aggregate of joints between the foot and shank segments) as the midpoint between the most medial and lateral prominences of the malleoli (Davis et al., 1991; Kadaba et al., 1990), yet research points to a slightly more distal location (Stagni et al., 2003; Leardini et al., 2000). Lundberg et al. (1989) placed tantalum beads in bones of the foot and shank in vivo, and obtained radiographs during loaded motion. Helical axes for both talocrural and subtalar joint rotations passed in close proximity to the centroid of the talus. This central "hub" was anatomically approximated by the midpoint of the most distal aspects of the malleoli. These 
findings support the use of a common, anatomically based, yet slightly more distal ankle joint center to capture the combined effects of the talocrural and subtalar joints. Ankle joint center identification based on the midpoint between the distal aspects of the malleoli has also Dustin A. Bruening, Ashlie N. Crewe, Frank L. Buczek received endorsement by the International Society of Biomechanics (Wu et al., 2002). However, the medial and lateral aspects are still used in most models primarily due to practical difficulty in working with skin mounted markers near the distal aspects, which are deep to several ligaments and adversely affected by soft tissue motion.

Joint centers are used in biomechanical models to define segment coordinate systems and mathematical articulation points about which joint moments can be resolved. The effects of inaccuracies in ankle joint center identification have received little attention in the literature, but may be important in some applications. In a study of six degrees-of-freedom (6DoF) joint powers during normal gait, Buczek et al. (1994) reported translational joint velocities when the conventional ankle center was used, and hypothesized that these were primarily due to an incorrect center of rotation. When an ankle joint center consistent with Lundberg et al. (1989) was used, these velocities were nearly eliminated for much of stance phase. Joint translations have been suggested as one measure of model validity (Kepple et al., 1994). At the ankle joint center, the distal shank (tibia and fibula) endpoint articulates with the proximal hindfoot (calcaneus) endpoint, and in the initial pose, these points are coincident. During movement, there is endpoint separation due to: (a) physio-logical translation within the ankle mortise itself (Sammarco et al., 1973), (b) errors from soft tissue and equipment noise, and (c) inaccuracies in the initial position of the joint center (Lu and O’Connor, 1999). Physiological motion and measurement errors are difficult to gauge precisely, but in general, the greater the inaccuracy in the calculated center of rotation, the greater will be the joint translations (Bruening and Richards, 2005). It follows that increasing the accuracy of the ankle joint center will reduce (but not eliminate) the joint translations.

The purpose of this study was to develop and evaluate an anatomically based correction that would move the conventional ankle joint center to a more accurate location, without requiring medical imaging or markers on the distal aspects of the malleoli. We hypothesized that common anthropometric measurements could be used to define the correction, and that its use would reduce calculated joint translations at the ankle joint during gait.

\section{Methods}

Weight-bearing coronal plane lower extremity radio-graphs from 30 pediatric patients (ages 7-16 yr, mean 10.5, SD 2.4) were randomly selected for analysis in a retrospective, human subjects exempt, study. Exclusion criteria were leg length discrepancy larger than $2.0 \mathrm{~cm}$, tibial epiphyseal plate fracture or growth arrest, varus/valgus deformity of the tibia, and other pathology likely to affect bony geometry, such as osteogenesis imperfecta and osteo-chondromatosis of the tibia.

Locations for conventional motion capture markers were estimated from the skin surface visible on the radio-graphs, and from these, virtual knee and ankle joint centers were derived (Fig. 1). The knee center (KC) was identified as the midpoint between the medial and lateral femoral epicondyles (ME and LE), while the conventional ankle center (AC) was similarly identified as the midpoint between the most medial and lateral aspects of the malleoli (MM and LM). A line was drawn between KC and AC, and extended inferiorly to intersect with a line drawn between the most distal aspects of the malleoli (MT and LT). The intersection of these two lines did not always fall precisely on the midpoint between MT and LT. However, the difference was considered to be negligible (generally under $0.5 \mathrm{~mm}$ ), and the 
intersection point was treated as the more accurate ankle joint center (AC0). Four distance measurements were then made to the nearest $0.5 \mathrm{~mm}$ using a ruler:

1. $\quad$ Knee width (KW): distance between ME and LE.

2. Ankle width (AW): distance between MM and LM.

3. Shank length (SL): distance between KC and AC.

4. $\quad$ Ankle center offset (Offset): distance between AC and AC0.

The relationships between Offset and each of the other three measures were investigated using bivariate linear regression analyses. The best correlated variable was then used to adjust the ankle joint center in the next part of the study.

To evaluate the performance of the regression equation providing the best correlation, a 6DoF multisegment foot model (Walker et al., 2008) was applied to existing gait data from eight normal pediatric subjects (ages 6-14), using both AC and AC0. Joint translations between the shank (tibia and fibula) and foot (calcaneus) segments were calculated in Visual3D (C-Motion, Inc., Rockville MD, USA) and averaged over one representative gait cycle for each subject. A two-tailed, paired t-test was used to detect differences in mean joint translations obtained using AC and AC0. Statistical analyses were performed using Microsoft Excel 2003.

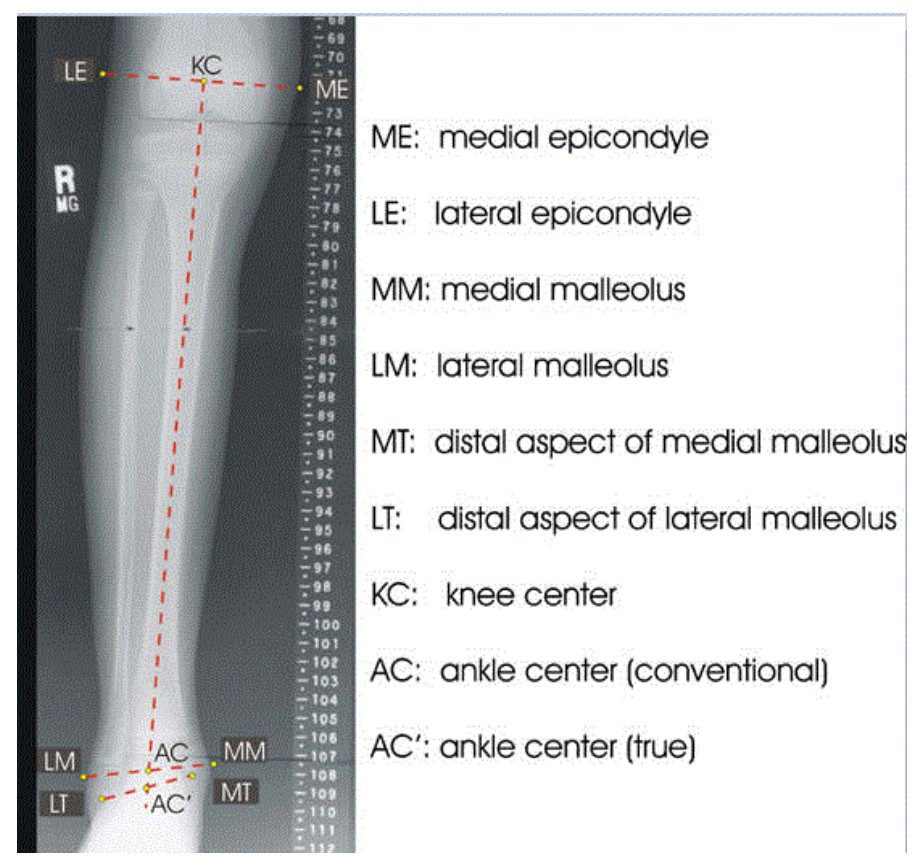

Fig. 1. Radiograph. Sample coronal plane lower extremity radiograph (11-year-old male subject). Physical marker locations were estimated at the skin surface, permitting derivation of virtual points at the knee and ankle joint centers.

\section{Results}

Offset measured on the 30 radiographs ranged from 6.0 to $13.0 \mathrm{~mm}$ (mean $9.7 \mathrm{~mm}$, SD 1.7). Of the three radio-graphic measurements, SL showed the best bivariate linear correlation with Offset, with a Pearson coefficient, $r$, of 0.89 ( 0.76 for $\mathrm{KW}$ and 0.71 for $\mathrm{AW})$. The line of best fit passed very close to the origin 
(Offset $=0.028 \mathrm{SL}-0.22 \mathrm{~mm}$ ), suggesting that a simple proportion of SL, achieved by forcing a zero $\mathrm{y}$ intercept (Fig. 2), would provide sufficient accuracy $(r=0.89)$ :

Offset $($ predicted $)=0: 027 \mathrm{SL} \quad(1)$

Using this equation, the mean error in predicting Offset for these 30 radiographs was $0.6 \mathrm{~mm}$ (6\% mean Offset), and the maximum error was $1.7 \mathrm{~mm}$ (18\% mean Offset). Individually, only seven subjects had prediction errors greater than $10 \%$ Offset. There was no appreciable difference in accuracy when the full regression equation was used (mean error also $0.6 \mathrm{~mm}$ ) rather than the simple proportion.

Mean joint translations during a gait cycle obtained using AC0 (1.8 mm, SD 0.5) were significantly smaller $(\mathrm{P}=0.0001)$ than those obtained using AC $(2.4 \mathrm{~mm}$, SD 0.6). These joint translations were reduced for each of the eight subjects (Fig. 3).

\section{Discussion}

The primary purpose of this study was to identify an anatomically based correction that would move the ankle joint center from a conventional, practical location to a more accurate but equally practical location. The high correlation of Offset with SL and the consistent reduction of joint translations for all subjects suggest that measurement errors were small, and that the correction achieved the desired results. The translations that were removed are due to an inaccurate joint center location; the remaining translations likely include true physiological motion. This anatomically based correction may be preferable to a mathematical algorithm, such as defining the joint center by minimizing the joint translation, which can result in a false minimum when true physiological translation is present.

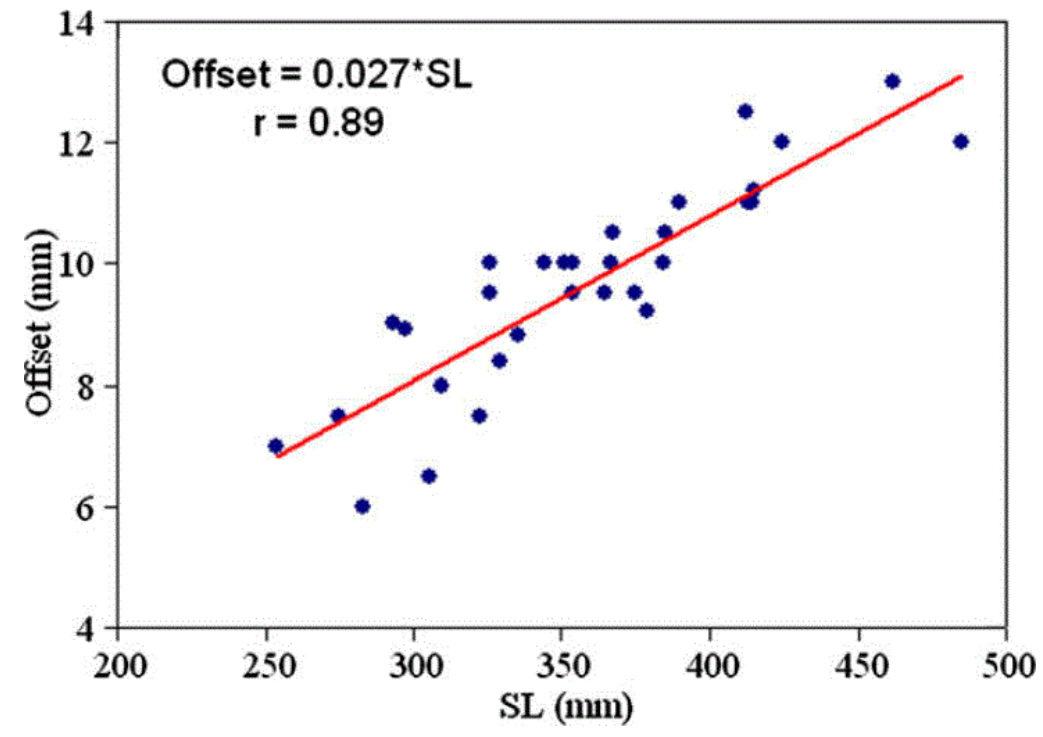

Fig. 2. SL Correlation. Scatterplot showing correlation between shank length (SL) and Offset. The regression equation and correlation coefficient, $r$, are included. 


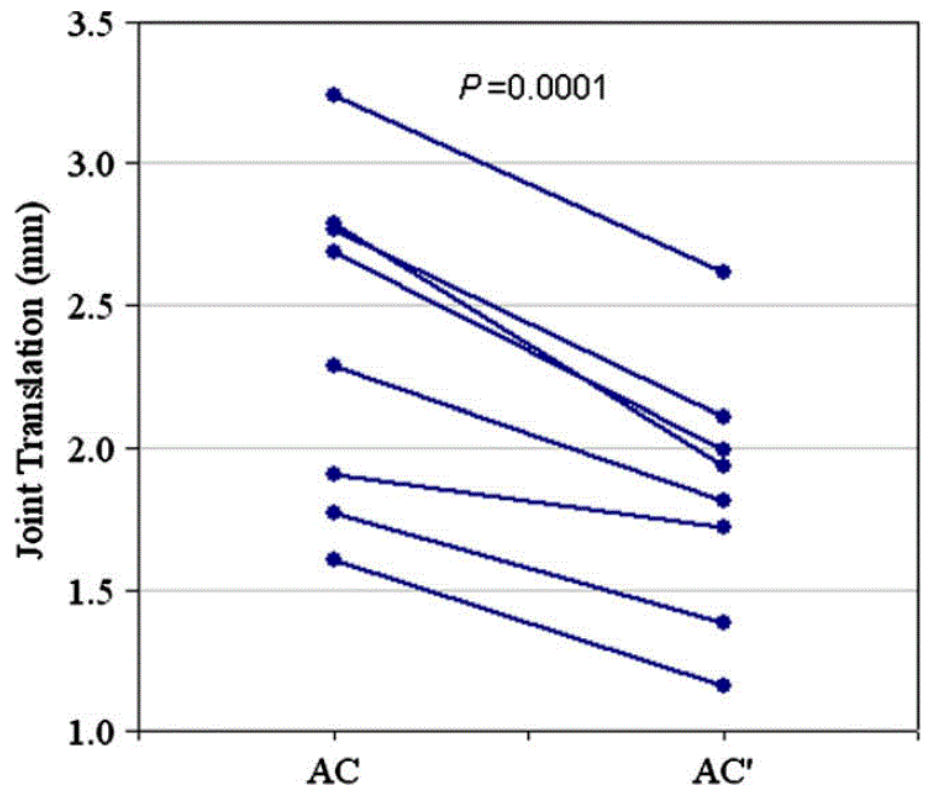

Fig. 3. Joint translations. Using a predicted ankle center between the distal aspects of the malleoli (ACO), rather than between the medial and lateral aspects (AC), mean joint translations during a gait cycle were reduced for all eight subjects.

Limitations to the study come from several sources. Radiographic measurement errors were possible from com-promised skin and landmark visibility on a few of the films as well as the inherent two-dimensional nature of the radio-graphs. Bone morphology and development may help to explain the lower correlations found in AW and KW. Although longitudinal bone growth ceases in the late teen-age years when the metaphyses ossify, localized bone remodeling continues to occur around the epiphyses and diaphysis due to mechanical and physiological factors (Urist, 1980). This remodeling presents as a greater propor-tion of AW and KW than of SL, making these width mea-sures more sensitive to variation among subjects, and therefore less predictive of Offset. The radiographs were taken from a pediatric population, but the results may still be applicable to adults. Full lower extremity radiographs that include both the ankle and knee are rarely collected for adults and this hinders a similar retrospective study in an adult population. However, the current study uses weight-bearing X-rays from children through age 16 . The correlations in this population appear valid through the ages during which longitudinal bone growth occurs, and extrapolation to adult populations may be warranted.

Regarding the utility of our work, the ankle joint center errors (Offsets) calculated in this study were fairly small (i.e., less than $13 \mathrm{~mm}$ ). Unlike joint center location errors at the hip, which have been shown to greatly affect hip joint angles and moments (Kirkwood et al., 1999; Stagni et al., 2000), the relatively small ankle joint center errors are unli-kely to have as great an effect on rotational kinematics and kinetics during normal gait. Although sensitivity analyses on these data are beyond the scope of this brief report, our observations suggest that the effects in normal gait are indeed small. Larger differences in pathological gait are possible and have not been investigated. In addition, greater benefits may lie in analyses of translational kine-matics and kinetics as well as in segment scaling for subject specific musculoskeletal simulations.

\section{References}

Bruening, D., Richards, J.G., 2005. Optimal ankle axis position for articulated boots. Sports Biomech. 4 (2), 215-225. 
Buczek, F.L., Kepple, T.M., Siegel, K.L., Stanhope, S.J., 1994. Translational and rotational joint power terms in a six degree-of-freedom model of the normal ankle complex. J. Biomech. 27 (12), 14471457.

Davis, R., Ounpuu, S., Tyburski, D., Gage, J., 1991. A gait analysis data collection and reduction technique. Hum. Mov. Sci. 10, 575-587.

Kadaba, M.P., Ramakrishnan, H.K., Wootten, M.E., 1990. Measurement of lower extremity kinematics during level walking. J. Orthop. Res. 8 m (3), 383-392.

Kepple, T.M., Arnold, A.S., Stanhope, S.J., Siegel, K.L., 1994. Assess- ment of a method to estimate muscle attachments from surface landmarks: a 3D computer graphics approach. J. Biomech. 27 (3), 365-371.

Kirkwood, R.N., Culham, E.G., Costigan, P., 1999. Radiographic and non-invasive determination of the hip joint center location: effect on hip joint moments. Clin. Biomech. 14 (4), 227-235.

Leardini, A., O’connor, J.J., Catani, F., Giannini, S., 2000. The role of the passive structures in the mobility and stability of the human ankle joint: a literature review. Foot. Ankle. Int. 21 (7), 602-615.

Lu, T.W., O’connor, J.J., 1999. Bone position estimation from skin marker co-ordinates using global optimization with joint constraints. J. Biomech. 32 (2), 129-134.

Lundberg, A., Svensson, O.K., Nemeth, G., Selvik, G., 1989. The axis of rotation of the ankle joint. J. Bone. Joint. Surg. Br 71 (1), 94-99.

Sammarco, G.J., Burstein, A.H., Frankel, V.H., 1973. Biomechanics of the ankle: a kinematic study. Orthop. Clin. North. Am. 4 (1), 75-96.

Stagni, R., Leardini, A., Cappozzo, A., Grazia Benedetti, M., Cappello, A., 2000. Effects of hip joint centre mislocation on gait analysis results. J. Biomech. 33 (11), 1479-1487.

Stagni, R., Leardini, A., O’connor, J.J., Giannini, S., 2003. Role of passive structures in the mobility and stability of the human subtalar joint: a m literature review. Foot. Ankle. Int. 24 (5), 402-409.

Urist, M., 1980. Fundamental and Clinical Bone Physiology. Lippincott Williams and Wilkins, Philadelphia.

Walker, M., Buczek, F., Cooney, K., Sharkey, N., Sanders, J., 2008. Multisegment foot biomechanics in dynamic hindfoot varus. In: Harris, G.F., Smith, P.A., Marks, R.M. (Eds.), Foot and Ankle Motion Analysis - Clinical Treatment and Technology. CRC Press, Taylor and Francis Group, LLC, Boca Raton.

Wu, G., Siegler, S., Allard, P., Kirtley, C., Leardini, A., Rosenbaum, D., Whittle, M., D’lima, D.D., Cristofolini, L., Witte, H., Schmid, O., Stokes, I., 2002. ISB recommendation on definitions of joint coordinate system of various joints for the reporting of human joint motion -part I: Ankle, hip, and spine. International Society of Biomechanics. J. Biomech. 35 (4), 543-548. 
NIOSH disclaimer: The findings and conclusions in this report are those of the authors and do not necessarily represent the views of the National Institute for Occupational Safety and Health. 